\title{
Coherent Function of Interrogative Mood Metaphor in Academic Discourse: Thematic Progression Pattern Perspective
}

\author{
Xu Wei, Zhang Yi* \\ School of Foreign Studies, Northwestern Polytechnical University, China \\ Received July 1, 2020; Revised July 23, 2020; Accepted August 28, 2020
}

\section{Cite This Paper in the following Citation Styles}

(a): [1] Xu Wei, Zhang Yi , "Coherent Function of Interrogative Mood Metaphor in Academic Discourse: Thematic Progression Pattern Perspective," Linguistics and Literature Studies, Vol. 8, No. 5, pp. 247 - 255, 2020. DOI: 10.13189/lls.2020.080503.

(b): Xu Wei, Zhang Yi (2020). Coherent Function of Interrogative Mood Metaphor in Academic Discourse: Thematic Progression Pattern Perspective. Linguistics and Literature Studies, 8(5), 247 - 255. DOI: 10.13189/lls.2020.080503.

Copyright $₫ 2020$ by authors, all rights reserved. Authors agree that this article remains permanently open access under the terms of the Creative Commons Attribution License 4.0 International License

\begin{abstract}
This paper investigated the coherent functions of interrogative mood metaphors in an academic context based on Halliday' model of mood metaphor [1] and Zhu's theory of thematic progression (TP) pattern [2]. With a focus on the strategies of linking the themes and rhemes in the metaphorical clause to those of surrounding clauses, this paper identified three main modes of information flow patterns. In the mood metaphor $(S)$ and the sentence before it (S-1), the information current is often progressed in a concentrated way since the metaphorical questions often serve as enforcements of its former sentence. Concentrated Progression is also often used in the $\mathrm{S}$ and the sentence after it $(\mathrm{S}+1)$ to answer the previous metaphorical questions, serving the purpose of appealing to authority. Besides, Constant Progression, as a simple liner pattern of message current, occurs in S and $\mathrm{S}+1$ to enhance the reading comprehensibility when introducing a concept to readers or to highlight the key viewpoints as evaluating the proposition in $\mathrm{S}$. This paper has pedagogical implications for academic reading and writing practices of native and non-native researchers.
\end{abstract}

Keywords Interrogative Mood Metaphor, Thematic Progression Pattern, Theme-Rheme Model, Coherence, Academic Discourse

\section{Introduction}

Coherence refers to the extent to which the readers or listeners are able to infer the writers' or speakers' communicative intentions. Different from the intra-clausal perspective of cohesion, coherence, as it were, not only focuses on how information is structured and linked at the textual level, but also indicates some interpersonal and interactional features beyond the textual level. Such an abstract semantic concept is difficult to understand for second language learners, let alone to put it into their writing practice, which may result from insufficient exposure to texts in the target language or the interference of their first language. Responding to this issue, a growing body of research on coherence [3-8] indicated the vital places of theme-rheme model and Thematic Progression (TP) theory in semantic coherence based on the assumption that theme and rheme, in thematic progression, "fan out across whole texts and indicates where topics begin and end, also points up a text's underlying organization" [7]. Thus, an understanding of theme and rheme elements in clauses and the patterns of thematic progression for combining these elements into stretches of discourse is essential for coherent writing. theme-rheme model and Thematic Progression (TP) theory were thereby widely applied in the analysis of coherence in academic discourse $[9,10]$. 
An interrogative mood metaphor is noted for the pattern of presenting an opinion as an interrogative with an immediate self-answer. This rhetorical nature enables it not only to connect the surrounding information within the text, but also to construct writer-reader interaction beyond the text. This coherent function has been largely supported by a growing body of research [9-17] that has investigated the use of the metaphorical interrogatives by members of different professional communities. Hyland [12], for instance, examined the use of rhetorical questions as engagement markers in a corpus of 240 research articles and identified the use of interrogatives as a coherent strategy in academic writings owing to its functions of dialogic involvement, inviting participation, encouraging curiosity and leading readers to the writer's viewpoint. In a similar vein, Soler [18] investigated the interrogative structure in 570 titles of research articles and confirmed interrogatives' interactional actions of engaging readers and expliciting viewpoints. The coherent function of interrogative was also observed in the studies on how texts were connected to the audience in news reports [13-18] and advertisement [19]. Despite a sustained interest in this metaphorical variant, few research has examined exactly how the mood metaphor constructs coherence in academic discourse, not to mention doing so from the TP pattern perspective. In this respect, the present study aims to analyze the coherent functions of interrogative mood metaphors in academic discourse by analyzing the TP patterns of the metaphorical expressions in their surrounding co-text.

\section{Mood Metaphor and Interrogative Mood Metaphor}

"Metaphor of mood is a variant of the speech function pattern and a mechanism for the expansion of speech function" [19]. Speech function is a complex system consisting of multiple pairs of semantic features. The transformation of those semantic features will lead to the generation of mood metaphors [21], including class shift and rank shift type. "Class shift" involves a shift of semantic features between "speech roles" (i.e. "give" and “command") or "commodity exchanged" (goods \& services and information). The two pairs of variables of "speech role" and "commodity exchanged" constitute four speech functions: statement, question, command, and offer [20: 68-69]. The category of speech function is embodied in the system of mood. Generally, the declarative mood expresses statements; interrogative mood illustrates questions; the imperative mood shows; and "offer" can be conveyed in several different moods. When a speech function is expressed in its incongruent forms of moods, the mood metaphor is generated. For example, a declarative mood used to express a question or command rather than a statement becomes a declarative mood metaphor.

Based on Table 1, the class shift mood metaphor consists of declarative mood metaphor, interrogative mood metaphor, and imperative mood metaphor. The current study focuses on interrogative mood metaphors, including the metaphorical statement and command.

The principle is to identify the metaphorical interrogatives by figuring out the clauses' speech functions through "expected responses" [1:137] (acknowledgment /contradiction for congruent declarative, answer/disclaimer for interrogative, undertaking/refusal for imperative).

(1) Have I ever let you down?

(2) Can you tell me the truth?

As we can see from the above examples, these interrogative sentences have interrogative mood. However, the implied meaning of example (1) is "I have never let you down," which is similar to rhetorical questions and does not require an answer. Its idealized response should be "acknowledgment" or "contradiction". Thus, its speech function can be defined as a statement. The interrogative mood of the sentence expresses the declarative function, so it is a metaphorical expression in the interrogative mood. The idealized response of Example (2) is "undertaking", which is to provide the service required by the other party -- telling the truth. Therefore, the speech function of the sentence is a command, which is the metaphorical expression of the interrogative mood projecting command.

Table 1. Typical and metaphorical realizations of speech functions in mood types

\begin{tabular}{|c|c|c|c|}
\hline speech function & statement & question & command \\
\hline declarative & I have never let you down & $\begin{array}{c}\text { I wonder where you have } \\
\text { been. }\end{array}$ & You should tell me the truth. \\
\hline interrogative & Have I ever let you down? & Where have you been? & Could you tell me the truth? \\
\hline imperative & $\begin{array}{c}\text { Admit that I have never let you } \\
\text { down! }\end{array}$ & $\begin{array}{c}\text { Tell me where you have } \\
\text { been! }\end{array}$ & Tell me the truth! \\
\hline
\end{tabular}

(From Fan [21:30] 


\section{Theme and TP Pattern}

"The Theme is the element that serves as the point of departure of the message. The remainder of the message, the part in which the Theme is developed, is called the Rheme" [1:89]. Halliday and Mattenshein [1:97-104] defined thematic structure of each kind of moods: declarative, interrogative (wh-, yes/no), and imperative clause. The theme is divided into the marked theme and unmarked type. The marked theme refers to "a Theme that is something other than the Subject, in a declarative clause" [1:98], such as adverbial groups (e.g. "today" and “suddenly”), or prepositional phrase (e.g. "at night” and "in the corner"). The unmarked theme refers to "the mapping of Theme on to Subject" [1:98]. The following table lists the examples of three kinds of clauses in detail (Table 2).

The current study applies Zhu's (1995) TP patterns which are frequently used. The four patterns with instances are shown as follows:

(1) Parallel progression: The themes in a series of sentences all are the first theme, but different rhemes are linked.

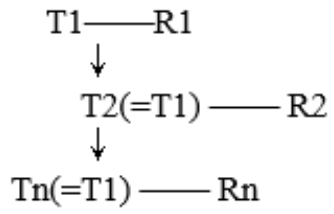

"These indices (T1) can be classified into five main categories, as listed in Table 1, based on the type of complexity (Lu, 2011). The indices (T2) in the first category-mean length of clause (MLC), mean length of sentence (MLS), and mean length of T-unit (MLT)—assess the length of a production at the clausal, sentential, or T-unit level." [22]

(2) Concentrated progression: Except for the first rheme, other rhemes are from the first rheme or part of the first rheme.

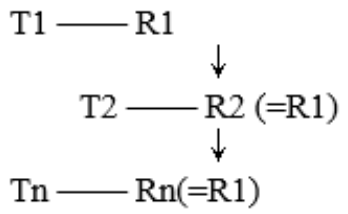

"A future challenge is to assess whether the language effects we have observed have any long-lasting consequences for our mental representations of caused motion events.(R1) For example, will priming effects transfer across a bilingual's languages?” (R2) [23]

(3) Constant progression: The rheme or part of rheme in the former sentence becomes the theme of the latter sentence.

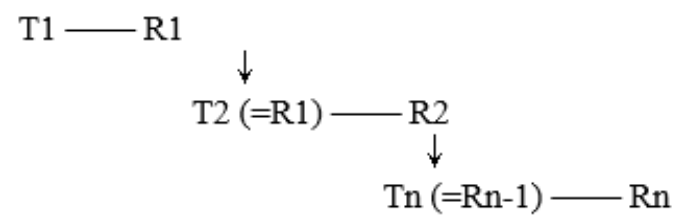

"Considering that recent research has pointed to the existence of disciplinary variation, by looking into the CARS model's applicability to the genre of the RA within the field of Agricultural Sciences, it is also my aim to assess and shed light on the rhetorical structure and the norms and/or conventions that guide the writing of this genre (R1). This (T2) will inevitably aid our understanding of it and contribute to the wider on-going research in the field of genre studies." [24]

(4) Intersection progression: The theme of the former sentence becomes the rheme of the latter sentence.

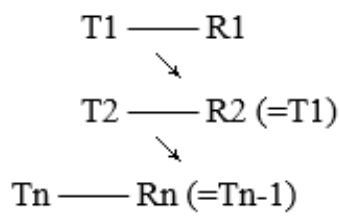

"Complexity (T1) in L2 language production has long been considered one of the most important constructs for assessing L2 performance, along with proficiency, accuracy, and fluency (Ellis, 2003, 2008; Ellis \& Barkhuizen, 2005; Larsen-Freeman, 1978; Skehan, 1989, 1998). According to Ellis (2003), complexity (R2) refers to "the extent to which the language produced in performing a task is elaborate and varied" (p. 340).” [24] 
Table 2. Thematic patterns of declarative, interrogative and imperative clauses

\begin{tabular}{|c|c|c|c|}
\hline Clauses & \multicolumn{2}{|l|}{ Theme } & Rheme \\
\hline \multirow{4}{*}{ Declarative } & \multicolumn{2}{|c|}{ Unmarked theme } & \multirow{2}{*}{$\begin{array}{l}\text { had a little nut-tree. } \\
\text { Lived in an oak. } \\
\text { Is a proper cup of coffee. }\end{array}$} \\
\hline & \multicolumn{2}{|c|}{$\begin{array}{l}\text { I } \\
\text { a wise old owl } \\
\text { what I want } \\
\end{array}$} & \\
\hline & \multicolumn{2}{|c|}{ Marked theme } & \multirow[b]{2}{*}{$\begin{array}{l}\text { we roll along. } \\
\text { I lost my wife. } \\
\text { We owe both to ourselves }\end{array}$} \\
\hline & \multicolumn{2}{|c|}{$\begin{array}{l}\text { merrily } \\
\text { on Saturday night } \\
\text { all this } \\
\end{array}$} & \\
\hline \multirow{4}{*}{$\begin{array}{l}\text { Interrogative } \\
\text { (wh-) }\end{array}$} & \multicolumn{2}{|c|}{ Unmarked theme } & \multirow[b]{2}{*}{$\begin{array}{l}\text { wants a glass of white wine? } \\
\text { Did you get that from? } \\
\text { Did you want? } \\
\text { 's she there for? } \\
\text { Was he opposed to coming in? }\end{array}$} \\
\hline & \multicolumn{2}{|c|}{$\begin{array}{l}\text { who } \\
\text { where } \\
\text { how many hours } \\
\text { and how long } \\
\text { why } \\
\end{array}$} & \\
\hline & \multicolumn{2}{|c|}{ Marked theme } & \multirow{2}{*}{$\begin{array}{l}\text { is it any wonder that motorists, for their own safety as well as that of other } \\
\text { road users, are reluctant to 'obey the signals of a police officer?' }\end{array}$} \\
\hline & \multicolumn{2}{|c|}{ In such circumstances, } & \\
\hline \multirow{4}{*}{$\begin{array}{l}\text { Interrogative } \\
\text { (yes/no) }\end{array}$} & Theme(1) & Theme(2) & \multirow[b]{2}{*}{$\begin{array}{l}\text { eat a whole packet of tim tams? } \\
\text { Got the car back by the way? } \\
\text { Sleep okay? } \\
\text { Make some toast? } \\
\text { Still together? }\end{array}$} \\
\hline & $\begin{array}{l}\text { Could } \\
\text { has } \\
\text { did } \\
\text { shall } \\
\text { are } \\
\end{array}$ & $\begin{array}{l}\text { you } \\
\text { he } \\
\text { you } \\
\text { I } \\
\text { they }\end{array}$ & \\
\hline & \multicolumn{2}{|c|}{ Marked theme } & \\
\hline & \multicolumn{2}{|c|}{ Except for music, } & what did they have in common? \\
\hline Imperative & \multicolumn{2}{|l|}{$\begin{array}{l}\text { let's } \\
\text { don't do } \\
\text { you }\end{array}$} & $\begin{array}{l}\text { do lunch at the Ivy. } \\
\text { That } \\
\text { take the office }\end{array}$ \\
\hline
\end{tabular}

\section{Thematic Patterns of Interrogative Mood Metaphors in Academic Discourse}

As we have noted in table 2, in a WH-interrogative, the typical unmarked theme is solely composed of the WH-elements (e.g. what), but if the WH-word is part of a nominal group, the nominal group may function as theme on its own (e.g. Which house do we live in?). It is slightly different with the situation in a yes/no interrogative, in which the unmarked theme (e.g. do you) not only includes finite operator (e.g. do) but also extends to the following Subject (e.g. you), since the finite operator is not accounted as an experiential element in the clause. In both kinds of metaphorical interrogatives, there is a strong tendency of the speaker or writer to choose an unmarked thematic pattern since it has developed into the means of loading basic information of the clauses.

Table 3. Unmarked theme in interrogatives

\begin{tabular}{|l|l|}
\hline What & $\begin{array}{l}\text { are the consequences of this perceptual } \\
\text { problem? }\end{array}$ \\
\hline Does an L2 & $\begin{array}{l}\text { have an influence on L3 speaking } \\
\text { proficiency and, if so, is its effect different } \\
\text { from L1 influence? }\end{array}$ \\
\hline Theme & Rheme \\
\hline
\end{tabular}

Marked themes do occur in interrogatives, especially in the academic context. Through introducing a marked theme in front of the interrogatives, authors leave a buffering phase for readers to react to their invitation for participating in the discussion and do not suddenly invite the readers into a question. Besides, marked themes are conjunctive adjuncts, usually in the forms of adverbial groups or prepositional phrases that relate the clause to the previous message and preceding text.

Table 4. Marked theme in interrogatives (conjunctive adjunct)

\begin{tabular}{|l|l|}
\hline In other words, & $\begin{array}{l}\text { how stable is FLA/FLCA across different target } \\
\text { languages? }\end{array}$ \\
\hline For example, & $\begin{array}{l}\text { might one student do well in Arabic but struggle } \\
\text { with Korean, or vice versa? }\end{array}$ \\
\hline Theme & Rheme \\
\hline
\end{tabular}

\section{Thematic Progression Patterns of Interrogative Mood Metaphors in Academic Discourse}

\section{Parallel Progression and Intersection Progression}

Parallel Progression and Intersection Progression are rare in those interrogatives. As we can note in the figures, 
the theme of the interrogatives, neither marked nor unmarked, is equivalent to the theme in S-1 or S+1 because the themes do not contain any experiential elements (participant/circumstance/process) that can be referred to. That is to say, $\mathrm{T}_{\mathrm{S}-1} \neq \mathrm{T}_{\mathrm{S}} \neq \mathrm{T}_{\mathrm{S}+1}$, which means parallel progression is probably absent in the co-text of interrogative mood metaphors. For the same reason, $\mathrm{Ts} \neq \mathrm{R}_{\mathrm{S}+1}$ suggest that intersection progression will not occur in the $S$ and $S+1$. But what we know about the lower utilization rate of intersection progression in $S$ and S-1 is largely based upon empirical evidence that revealed the fertile genre for the intersectional pattern is narratives but not informative research articles [25-26]. This genre-preference may be due to its undulating flow of information, which is more suitable to tell an intricate and gripping story than to present a quite logical, coherent, and informative scientific report.

Thus, in the following part, Concentrated and Constant patterns of information progression will be investigated in detail.

\subsection{The Application of TP Patterns in S-1 and S}

In the S-1 and S, since the theme of S is usually a non-topical theme, the theme is often not related to the rheme in S-1, thus, the constant pattern seldom occurs in this situation.

\section{Concentrated progression}

We find that the interrogative mood metaphor is always used to be the explanation or enforcement of its previous sentence to achieve semantic clearness or explicity. Usually the metaphorical expressions serve as examples (as in example (1) and (2)), or restatements (as in example (3) and (4)). In this way, the explanation part of two sentences, which are usually the rheme elements, will be similar or accessioned with each other. Thus, the TP patterns in two sentences often turn out to be concentrated progression.

(1) "Although available aptitude tests have been validated with adult learners of diverse L2s, to date no test can determine whether a particular student's aptitude may vary for different L2s (R1). For example, might one student do well in Arabic but struggle with Korean, or vice versa?"(R2) [27]

(2) "A future challenge is to assess whether the language effects we have observed have any long-lasting consequences (R1) for our mental representations of caused motion events. For example, will priming effects transfer across a bilinqual's lanquages?” (R2) [25]

In the above two examples, the interrogative mood metaphors are used as instances to further illustrate the sentences preceding them. The former sentence in the first pair of sentences, the "student's aptitude may vary for different L2s" in the former sentence is elaborated by the "one student do well in Arabic but struggle with Korean, or vice versa" in the latter. As for the second pair, the "long-lasting consequences" in the previous sentence is exemplified by "priming effects transfer across a bilingual's languages” in the following sentence. Based on the TP pattern theory, annotated themes and rhemes of the two sentences are graphically illustrated below:

$$
\mathrm{T} 2 \stackrel{\mathrm{T} 1-\mathrm{R} 1}{-\mathrm{R} 2(=\mathrm{R} 1)}
$$

(3) "One could object that learners might experience more or less FLA/FLCA (R1) depending on the language or even the FL teacher. In other words, how stable is FLA/FLCA (R2) across different target languages?" [28]

(4) "Research on bi- and multilingualism is increasingly focused on whether language learning affects cognition (R1) beyond language itself. That is, does learning a new language affect mental processes such as perception, cateqorization, similarity assessment, memory recognition, and reasoning?' (R2) [25]

As mentioned above, metaphorical expressions are applied as restatements of their previous sentences. In the example (3), "how stable is FLA/FLCA" in the latter sentence is the substitution of "more or less FLA/FLCA" in the former sentence. As for the fourth example, rheme "cognition" in the first sentence is further explained by the rheme "perception, categorization, similarity assessment, memory recognition, and reasoning" in the second sentence. We may find that this concentrated pattern in the sentence pair helps to illustrate the concept in the first sentence. This pattern leads readers to learn more knowledge of exemplification by using interrogative mood metaphor to reach discourse explicity and coherence.

Other situations also account for the choice of this coherent pattern. Sometimes authors tend to ask a series of "questions" from different perspectives to make it clear in meaning. For instance,

(5) "Why does L2 aptitude predict advanced - level L2 Chinese performance (R1) so poorly? What is it that distinguishes performance at the advanced level?" (R2) [29]

This example is extracted from the discussion part of an RA. The author of the RA arose two questions successively in order to make himself clear. We may find that these two interrogative metaphors of mood have the same focus "the performance of advance level" which is the rheme part. Their themes, however, turn out to be different to avoid repetition. Actually, the second sentence is a further explanation of the first one. In this way, the concentrated progression is employed. 


\subsection{The Application of TP Patterns in $S$ and $S+1$}

Concentrated progression

The metaphorical pattern is similar to a rhetorical question so its following part is usually an answer of the “question”. In answering this, academic writers would appeal to authority or report others' research findings, which could craft the objectivity and pervasiveness of their texts. Therefore, in the mood metaphors' successive sentences, these sources of answer become the themes, with typical evidential expressions like "Evidence suggests...”, “Someone indicates...”, "Literature documents..." etc. The content of the proposition becomes the rheme, which is the real informational part associated with the rheme of the previous metaphorical question. In this sense, the information flows in the way of concentrated progression pattern. For instances,

(6) "That is, is there really a single latent trait that can reliably predict advanced - level language skills or L2 skills acquired through nonintense or more naturalistic conditions(R1)? Researchers may have pinned their hopes on working memory as a promising additional component of L2 aptitude that reliably predicts advanced proficiency, but initial research is inconclusive (R2). More studies are needed. " [29]

(7) "In other words, how stable is FLA/FLCA across different target languages (R1)? Saito et al. (1999) compared FLCA and Foreign Language Reading Anxiety (FLRA) scores from 383 American first-semester students in French, Japanese, and Russian and discovered non-significant differences for FLCA between the groups (R2)." [28]

In the above two examples, the sentences following the interrogative mood metaphors start with "Researchers" and "Saito et al.", followed with their research results, which are the rheme parts. These rhemes are partial repetitions of rheme in the former sentences. And the annotated themes and rheme are graphically explained at below:

$$
\begin{aligned}
& \mathrm{T} 1-\mathrm{R} 1 \\
& \mathrm{~T} 2-\mathrm{R} 2(=\mathrm{R} 1)
\end{aligned}
$$

The academic authors designed this way of information flow to enhance the objectivity and persuasiveness of their answers to the interrogative metaphorical expressions. Let us look at another two examples:

(8) "That is, does learning a new language affect mental processes such as perception, categorization, similarity assessment, memory recognition, and reasoning? (R1) A growing body of evidence suggests that learning a new language indeed affects the way we think about reality in a variety of domains (see Bylund \& Athanasopoulos, 2014b, for a recent overview)." (R2) [25]
(9) “If speakers of different languages think differently to a certain extent, what happens when you learn a new language(R1)? The available literature has documented two major patterns of cognitive restructuring in bilinguals: conceptual convergence and conceptual switching (R2) (see Pavlenko, 2005, for theoretically possible patterns). ” [25]

Both of these two instances are patterned in concentrated progression. The writers aim to get support from other researches with the expression "A growing body of evidence" and "The available literature". It explicitly shows to their readers that their propositions are reliable and have been widely recognized.

\section{Constant progression}

In the previous section, we explained the reason for answering the metaphorical question in the way of concentrated progression. However, the answer can also be offered more explicitly and directly as in constant progression. It depends on the writers' communicative purposes: If the writers want to stress the source of the information, they would prefer concentrated progression; however if they tend to emphasize the information itself, constant progression is a better choice for them since it is the easiest way for readers to connect the information in a co-text. Typically in the theoretical framework, interrogative mood metaphors are usually applied to offer the introduction of some important concepts to readers. For instance,

(10) "How can we operationalize imagery capacity (R1) and sensory preferences for research purposes? The term "imagery capacity" (T2) in this article bears the same meaning as the concept of "imagery ability" in sports psychology, where it is defined as "an individual's capability of forming vivid, controllable images and retaining them for sufficient time to effect the desired imagery rehearsal" (Morris, 1997, p. 37).” [30]

"The term imagery capacity" is the theme in the second sentence, which is a partial repetition of the rheme in the first sentence. Thus, the writer leads to the explanation of the concept "imagery capacity" in a coherent and direct way. Here, the purpose of the writer is to make the readers clear about his or her theoretical basis and his emphasis is the concept itself, rather than the source of the definition. Thus, he or she chooses the constant progression which is easy for readers to follow the writer's flow of information. The annotated theme and rheme are shown as follows:

$$
\begin{aligned}
& \mathrm{T} 1-\mathrm{R} 1 \\
& \mathrm{~T} 2(=\mathrm{R} 1)-\mathrm{R} 2
\end{aligned}
$$

It is also found that in some circumstances, writers do not answer the question immediately; as they rather tend to comment on those questions. The purpose is to show 
the significance of the "questions". It should be noted that the "question" is always the key issue in which writers want to engage their readers. In this circumstance, the theme of the S+1 usually refers to the rheme in the S. Thus, a constant progression pattern of information flow is generated. For example,

(11) "Does the mind structure L2 knowledge in a similar way as it structures L1 knowledge (R1)? This is a relevant question (T2) because L1-L3 typological similarity can be of lower importance than L2-L3 similarity for learning an L3 (Bardel \& Falk, 2007)." [31]

(12) "Do speakers of different languages think differently (R1)? This issue (T2), known as the principle of linguistic relativity (Whorf, 1956), has generated vigorous debate in the cognitive sciences (e.g., Levinson, 2003; Pinker, 1994).” [25]

(13) "For example, might one student do well in Arabic but struggle with Korean, or vice versa (R1)? This type of differential prediction (T2) is challenging, because languages vary along many dimensions including their typological distance from the native language (L1) and the relative complexity of their orthographic, phonological, and syntactic systems (see Mac Whinney, 1996, for a review of these issues)." [30]

In the above three examples, the themes are "This is a relevant question", "this issue" and "this type of differential prediction" which respectively connect to the rhemes in the former sentences. The writers evaluate the questions "relevant", “debatable”, and "challenging”, which indicates the value and significance of their arisen issues and their studies. For this purpose, the writers applied the constant progression to lead the information flow. Below is the graphical illustration of the annotated themes and rhemes:

$$
\begin{aligned}
& \mathrm{T} 1-\mathrm{R} 1 \\
& \mathrm{~T} 2(=\mathrm{R} 1)-\mathrm{R} 2
\end{aligned}
$$

Based on the above discussion, the three major modes of information flow in the co-text of the interrogative mood metaphor are summarized in the following figure.

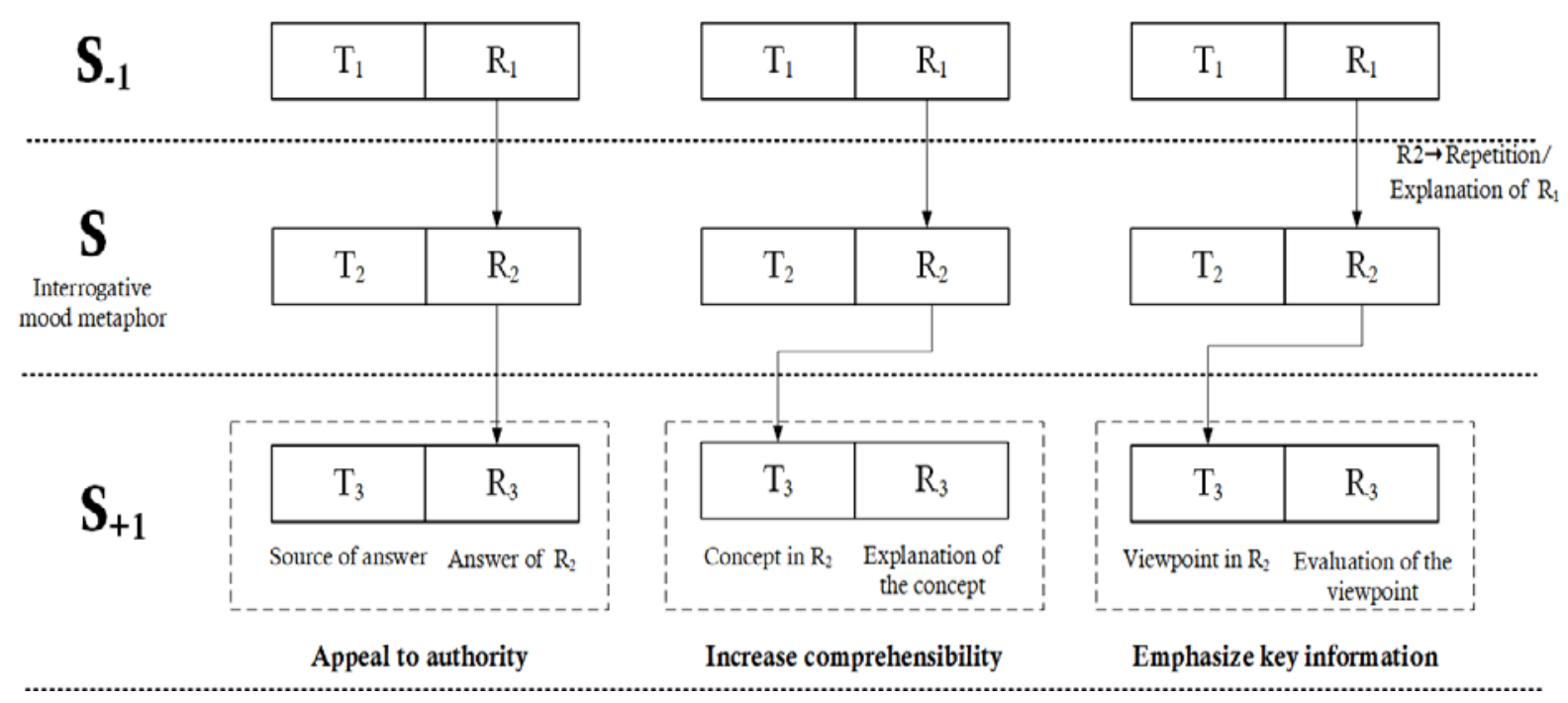

Figure 1. The three modes of information flow in the co-text of interrogative mood metaphor 


\section{Conclusions}

Drawn on the TP pattern theory, this study investigated the information flow of interrogative mood metaphor in academic discourse. Parallel Progression and Intersection Progression patterns are seldom applied in the co-text of those interrogatives for the reason that the theme of interrogatives $\left(\mathrm{T}_{\mathrm{S}}\right)$ does not contain any experiential elements (participant/circumstance/process) that can be related to the $T_{\mathrm{S}-1}, T_{\mathrm{S}+1}$, and $\mathrm{R}_{\mathrm{S}+1}$. Another possible explanation of the lower utilization of intersection progression is that it produces an uneven flow of information, which is not suitable to perform a logical, coherent and informative scientific report. Instead, concentrated and constant progression are better choices for academic authors. In the mood metaphor (S) and the sentence before it (S-1), concentrated progression frequently occurs because interrogative metaphors often serve as the explanation or enforcement of $\mathrm{S}-1$, which connects the rhemes of two sentences. In the $S$ and $S+1$, according to the communicative purposes of academic authors, two TP patterns are assigned with different missions. Concentrated progression appears for the reason that the academic authors tend to emphasize the source of information when answering the metaphorical questions. However, constant progression is a better choice in the situation that writers emphasize the information itself when explaining a concept to readers since it is the easiest pattern for readers to connect the information in co-text. Apart from increasing comprehensibility, constant progression serves the function of emphasizing the significance of the "question" in the sense that it constructs an information path $\left(\mathrm{R}_{\mathrm{S}}=\mathrm{T}_{\mathrm{S}+1}\right)$ for the authors to evaluate the questions.

Based on the results and discussions of this study, there are some implications of the current study. Firstly, this study has investigated how coherence is achieved by mood metaphors in linguistic RAs from the perspective of mood metaphor, which extends the applicable range of mood metaphor as well as TP pattern. Besides, this study contributes to improving second language learners' abilities to comprehend and produce interrogative mood metaphors in linguistic RAs. The TP patterns in S and S-1 reveal the way academic writers put forward metaphorical expressions, and the TP patterns in $\mathrm{S}$ and $\mathrm{S}+1$ show how the authors answer the interrogative mood metaphor naturally. Thus, it helps second language learners to better construct coherence through interrogative mood metaphors in their academic writings. Besides, the examples show the flexible application of interrogative mood metaphors in different situations based on authors' needs. It is, therefore, beneficial for second language learners to use different TP patterns effectively to construct various functions of mood metaphor according to their communicative purposes in their process of academic writing.
As for the limitation of the study, it has to be acknowledged that the present study only employed the means of qualitative analysis. Thus, it is desirable for further studies to adopt quantitative investigations to see the coherent function of the metaphorical variant in a large corpus.

\section{Acknowledgements}

This study is sponsored by the Seed Foundation of Innovation and Creation for Graduate Students in Northwestern Polytechnical University (No.CX2020033).

\section{REFERENCES}

[1] M.A.K. Halliday, C. Matthiessen. Halliday's Introduction to Functional Grammar (4th edition), Routledge, Londan, 2014.

[2] Zhu Yongsheng. Patterns of thematic progression and text analysis, Foreign Language Teaching and Research, No.3, 6-12, 1995.

[3] Yang, X. Thematic progression analysis in teaching explanation writing, Engl. Lang. Teach. Vol.1, No.1, 29-33, 2008.

[4] F. Danes. Functional sentence perspective and the organization of the text, Academia, Prague, 1974.

[5] F. Danes. The paragraph e a central unit of the thematic and compositional build-up of texts. In: Wårvik, B., Tanskanen, S.-K., Hiltunen, R. (Eds.), Organisation in Discourse. Anglicana Turkuensia, University of Turku, Finland,Turku, 29-40, 1995.

[6] T.P. Hawes. Thematic progression in the writing of students and professionals, Ampersand, Vol. 2, 93-100, 2015.

[7] T.P. Hawes. Thematic progression and rhetoric in sun and times editorials: 1991-2008, Rice Working Papers in Linguistics, No.2, 39-51, 2010.

[8] Feng Junying. A Survey of the Thematic Structure of Research Paper Abstracts, Journal of Language and Literature Studies, No. S1, 134-136, 2006.

[9] K. Hyland. What do they mean?, Questions in academic writing Text, Vol.22, No.4, 529-557, 2002.

[10] K. Hyland. Disciplines and discourses: social interactions in the construction of knowledge. In Starke-Meyerring, Doreen, Paré, Anthony, Artemeva, Natasha, Horne, Miriam, and Yousoubova, Larissa (Eds.). Writing in the knowledge society, p. 193-214. Parlor Press, WAC Clearinghouse, 2011.

[11] Weng Yulian, Stylistic markedness of news comment headlines, Journalism and Mass Communication Monthly, No.3, 83-85, 2011.

[12] Liu Chenyu, The stylistic value of grammatical metaphor, Modern Foreign Languages(Quarnerly), Vol.26, No.2, 120-127, 2003. 
[13] Hou Chunjie. The textual realization function of grammatical metaphor, Journal of Xi'an International Studies University, No.3, 5-9, 2006.

[14] Shen Jirong. The working mechanism and function of grammatical metaphor in news discourse, Contemporary Rhetoric, No.2, 85-91, 2010.

[15] Zeng Xiaoguang. Grammatical metaphor in English newspaper articles, Journal of Inner Mongolia Agricultural University (Social Science Edition), Vol.9, No.6, 369-372, 2017.

[16] Zeng Xiaoguang. Reinterpretation of grammatical metaphor in newspaper English, Foreign Language Learning Theory and Practice, No.3, 29-31, 2008.

[17] An Analysis of Interpersonal Meaning in Advertising Discourse from the Perspective of Mood Metaphor, Journal of Southwest University (Social Sciences Edition), Vol.36, No.6, 146-149, 2010.

[18] V. Soler. Writing Titles in Science: An Exploratory Study, English for Specific Purposes, Vol.26, No.1, 90-102, 2007.

[19] Yang Caiying. Metaphors of mood: A Mechanism for Expanding Speech Functions, Foreign Languages Research, No.3, 1-5,2006.

[20] M. A. K. Halliday. Introduction to Functional Grammar. Edward Arnold, London, 1994.

[21] Fan Wenfang. Metaphors of Mood in English, Journal of Foreign Languages, No.4, 29-34, 2000.

[22] Haerim Hwang, Hyeyoung Jung, Hyunwoo Kim. Effects of Written Versus Spoken Production Modalities on Syntactic Complexity Measures in Beginning-Level Child EFL Learners, The Modern Language Journal, Vol.104, No.1, 2020.

[23] Guillermo Montero-Melis, T. Florian Jaeger, Emanuel Bylund. Thinking Is Modulated by Recent Linguistic
Experience: Second Language Priming Affects Perceived Event Similarity, Language Learning, Vol.63, No.3, 636665, 2016.

[24] M. Milagros del Saz Rubio, A pragmatic approach to the macro-structure and metadiscoursal features of research article introductions in the field of Agricultural Sciences, English for Specific Purposes, Vol.30, No.4, 258-271, 2011.

[25] Guo Fang. Thematic progression and thematic structure of informative English Abstracts, Foreign Language Learning Theory and Practice, No.3, 41-46, 2007.

[26] K. Nwogu, T. Bloor. Thematic progression in professional and popular medical texts. In Functional and Systemic Linguistics. Berlin, Boston: De Gruyter Mouton.369-384, 1991.

[27] Anita R. Bowles, Charles B. Chang, Valerie P. Karuzis. Pitch Ability as an Aptitude for Tone Learning, Language Learning, Vol.66, No.4, 774-808, 2016.

[28] Jean-Marc Dewaele. The Link Between Foreign Language Classroom Anxiety and Psychoticism, Extraversion, and Neuroticism Among Adult Bi- and Multilinguals, The Modern Language Journal, Vol.97, No.3, 670-684,2013.

[29] Paula Winke. An Investigation into Second Language Aptitude for Advanced Chinese Language Learning, The Modern Language Journal, Vol.97, No.1, 109-130, 2013.

[30] Zoltán Dörnyei, Letty Chan. Motivation and Vision: An Analysis of Future L2 Self Images, Sensory Styles, and Imagery Capacity Across Two Target Languages, Language Learning, Vol.66, No.3, 437-462, 2013.

[31] Job J. Schepens, Frans van der Slik, Roeland van Hout. L1 and L2 Distance Effects in Learning L3 Dutch, Language Learning, Vol.66, No.1, 224-256, 2016.

[32] Farquhar C, Protein and DNA Music, Online available from http://www.hrpub.org 